\title{
A NUMERICAL SIMULATION STUDY TO DEVELOP AN ACCEPTABLE WAKE ENCOUNTER BOUNDARY FOR A B737-100 AIRPLANE
}

\author{
- Dan D. Vicroy* \\ Truc Nguyen ${ }^{\dagger}$ \\ NASA Langley Research Center \\ Hampton, Virginia
}

\section{Abstract}

The National Aeronautics and Space Administration (NASA) is conducting research with the goal of enabling safe improvements in the capacity of the nation's air transportation system. The wake-vortex upset hazard is an important factor in establishing the minimum safe spacing between aircraft during landing and take-off operations, thus impacting airport capacity. A batch simulation study was conducted to assess the sensitivity of various safe landing criteria in the development of an acceptable wake encounter boundary. A baseline six-degree-of-freedom simulation of a B737-100 airplane was modified to include a wake model and the vortex-induced forces and moments. The guidance and control input for the airplane was provided by an auto-land system. The wake strength and encounter geometry were varied. A sensitivity study was also conducted to assess the effects of encounter modeling methods and accuracy.

\section{$\underline{\text { Nomenclature }}$}

$C_{l} \quad$ rolling moment coefficient

$C_{t_{\beta}} \quad$ rolling moment due to sideslip coefficient

$C_{L} \quad$ lift coefficient

$C_{L_{\alpha}} \quad$ lift coefficient change with angle of attack

$C_{\beta} \quad$ yawing moment due to sideslip coefficient

$C_{Y} \quad$ sideforce coefficient

$C_{Y_{\beta}} \quad$ sideforce due to sideslip coefficient

$h_{w} \quad$ altitude of the wake above the runway, $\mathrm{ft}$

$r_{c} \quad$ vortex core radius, $\mathrm{ft}$

$r \quad$ radius from vortex center, $\mathrm{ft}$

* Research Engineer, Senior Member ALAA

$\dagger \quad$ Engineering Cooperative Education Student

Copyright $(1) 1993$ by the American Institute of Aeronautics and Astronautics, Inc. No copyright is asserted in the United States under Title 17, U.S. Code. The Government has a royalty-free license to exercise all rights under the copyright claimed herein for Government purposes. All other rights are reserved by the copyright owner. $\nu \quad$ velocity component along $Y$ axis, $\mathrm{ft} / \mathrm{s}$

$V_{\theta} \quad$ vortex tangential velocity, $\mathrm{ft} / \mathrm{s}$

$w \quad$ velocity component along $Z$ axis, $\mathrm{ft} / \mathrm{s}$

$X \quad$ longitudinal axis

$y \quad$ coordinate along $Y$ axis, $\mathrm{ft}$

$y_{w} \quad$ lateral coordinate of the wake, $\mathrm{ft}$

$Y \quad$ lateral axis

$z \quad$ coordinate along $\mathrm{Z}$ axis, $\mathrm{ft}$

$Z \quad$ vertical axis

$\delta_{w} \quad$ roll control power ratio

$\Gamma \quad$ vortex circulation strength, $\mathrm{ft}^{2} / \mathrm{s}$

\section{Subscripts}

auto referenced to the autopilot system

$b \quad$ reference to body axis system

$L \quad$ reference to left or port vortex

max wheel with maximum wheel input

no wake with no wake present

$p \quad$ reference to point $P$

rwy reference to runway axis system

$R \quad$ reference to right or starboard vortex

$w \quad$ wake-induced component

wake with wake present

\section{Introduction}

Many of today's major airports are capacity limited, leading to increased airport congestion and delays. The ability to relieve the congestion through airport expansion or new airport construction is limited and increasingly difficult. The National Aeronautics and Space Administration (NASA), the Federal Aviation Administration (FAA), airport operators, and the airline industry are all interested in methods to improve airport capacity. The NASA is conducting a Terminal Area Productivity (TAP) Program to provide the necessary research to support the FAA and industry in safely achieving clear-weather (visual flight rules) airport capacity in instrument meteorological conditions (IMC). The TAP Program consists of four elements: Air Traffic Management, Aircraft-Air Traffic Control Systems 
Integration, Low-Visibility Landing and Surface Operations, and Reduced Spacing Operations.

The wake vortex research described in this paper is a part of the Reduced Spacing Operations element of the TAP Program. Improvements in landing frequency through reduced in-trail spacing have the potential to improve system capacity by $10-15 \% .^{1}$ This potential capacity improvement has renewed interest in wake vortex research. ${ }^{2}$ The spacing required to avoid the wake turbulence of the preceding airplane is one of the limiting factors in safely reducing in-trail spacing.

The need for sufficient spacing between aircraft to insure an acceptable vortex encounter upset is not exceeded is most critical for aircraft near the ground during landing and takeoff. ${ }^{3}$ The degree of upset mainly depends on the relative size of the vortex generating and vortex penetrating airplane, and the extent the wake decay imparted by the atmosphere. The vortex initial energy or strength and the resulting response to a wake are directly related to aircraft size and weight.

The knowledge base on which current wake-vorteximposed separation standards are based evolved during the late 1960's and the 1970's. Currently, the U.S., aircraft are classified as "Heavy" $(300,000 \mathrm{lb}$. or greater), "Large" (between 12,500 and 300,000 lb.), and "Small " (less than 12,500 lb.) based on maximum gross takeoff weight. ${ }^{3,4}$ Although technically a large aircraft by weight, the B757 is currently given a special classification when it is the lead aircraft. The separation distances are based only on the classifications of the leading airplane and the following airplane. No account is made for factors such as airplane configuration or actual weight, wing span, atmospheric turbulence and winds, or local terrain effects. Therefore, the ability to accurately model the wake hazard and determine safe separation distances for a wide range of aircraft, weather, and operational scenarios may provide the basis for significant increases in airport capacity.

One of two conditions must be met to safely reduce the spacing between aircraft. The wake of the preceding aircraft must have either transported out of the intended flight path of the following airplane or it must have sufficiently decayed such that the encountering airplane can safely land. It is the determination of what constitutes sufficient decay that this study will address. This simulation study tested various safe landing criteria to define the wake decay required for a B737-100 airplane to safely encounter a wake and land under the guidance of an auto-land system. The wake strength and encounter geometry were varied to establish a safe encounter boundary. A sensitivity study was also conducted to assess the effects of modeling methods and accuracy.

\section{Previous Wake Encounter Simulation Research}

A number of vortex-encounter simulations were performed during the 1970s and 1980s. Among these, three studies stand out as particularly relevant to this simulation. In 1974, Nelson and McCormick ${ }^{6}$ studied vortex encounters with a batch simulation using analytical transfer functions to represent the pilot. Sammonds, Stinnet, and Larson ${ }^{8}$ used a piloted wake encounter simulation to establish hazard criteria from pilot opinion. Hastings and Keyser ${ }^{9}$ used a piloted simulation to study the effect of vortex decay on the initial response of a twin-engine transport. Each of these simulation studies used strip theory to model the wake effect on the airplane. The same method was used in this study and will be discussed later. These simulations differed from this study in that they were primarily focused on defining what constitutes a hazardous wake encounter. The goal of this study is to assess the sensitivity of candidate criteria to define an acceptable or safe wake encounter. In particular, the encounter must be weak enough that the airplane can continue the approach and landing without undue upsets to the passengers and crew.

\section{B737-100 Wake Encounter Simulation}

The baseline B737-100 simulation was a batch version of the six-degree-of-freedom real-time simulation of NASA Langley's Advanced Transport Operating System research airplane. The baseline simulation was modified to include the wake model and the strip-theory calculation of the vortex-induced forces and moments. Instead of using a pilot model, the control inputs were generated from an auto-land system. ${ }^{5}$ The maximum control authority available to the auto-land system was less than the full control authority of the airplane. This is typical of most autopilot systems. The maximum roll-control available to the auto-land system was $37.4 \%$ of the full rollcontrol authority of the airplane. This may result in acceptable encounter boundaries that are considered overly conservative to a pilot flying the landing. However, if automatic landings are to be performed under reduced separation conditions then acceptable encounter criteria must reflect the limits of such a system. 


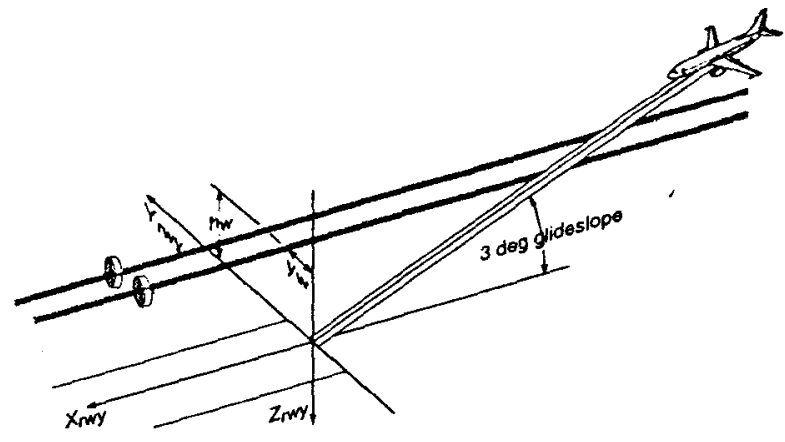

Figure 1. Wake encounter simulation geometry.

The geometry of the encounter simulation is shown in figure 1. The airplane was initially trimmed for a $3^{\circ}$ glideslope approach to landing at 137 knots and flaps set at $40^{\circ}$. It began 24,000 feet out from the runway threshold, at an altitude of 1,323 feet, and was correctly centered on the localizer and glideslope. A pair of vortices stretched from 24,300 feet before the runway threshold to 10,000 feet after the threshold. The altitude of the wake $\left(h_{w}\right)$ and the lateral placement $\left(y_{w}\right)$ was fixed for each encounter simulation. The wake altitude was varied from 1200 to 25 feet. The lateral placement of the wake was also varied to determine the location at which the landing criterion was most sensitive.

\section{Wake Model}

An empirically derived two-dimensional wake vortex model was used to describe the wake of the generating airplane. This wake model was proposed by Burnham in reference 2 to fit field measured data of airplane wakes. The model was defined in the inertial axis system by the circulation $(\Gamma)$, core radius $\left(r_{c}\right)$ and location $(y, z)$ of two counter-rotating vortices, as shown in figure 2 .

The wake model defines the tangential velocity $\left(V_{\theta}\right)$ of a single vortex as:

$$
V_{\theta}=\frac{\Gamma}{2 \pi}\left(\frac{r}{r_{c}^{2}+r^{2}}\right)
$$

where $r$ is the radius from the center of the vortex. The sidewash $(v)$ and downwash $(w)$ velocity components at a point $\mathrm{P}$ are obtained by summing the contributions of the left and right vortices.

$$
v=\frac{1}{2 \pi}\left[\Gamma_{R}\left(\frac{z_{p}-z_{R}}{r_{c_{R}}{ }^{2}+r_{R}^{2}}\right)-\Gamma_{L}\left(\frac{z_{p}-z_{L}}{r_{c_{L}}{ }^{2}+r_{L}{ }^{2}}\right)\right]
$$

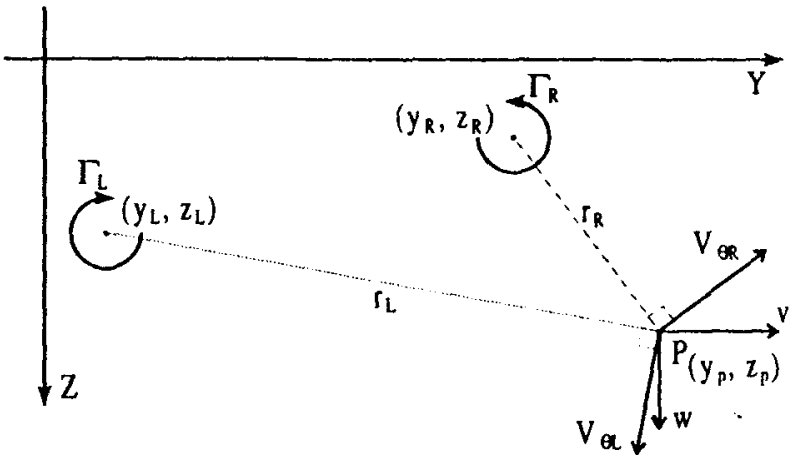

Figure 2. Two-dimensional wake model.

$$
w=\frac{1}{2 \pi}\left[\Gamma_{L}\left(\frac{y_{p}-y_{L}}{r_{c_{L}}{ }^{2}+r_{L}{ }^{2}}\right)-\Gamma_{R}\left(\frac{y_{p}-y_{R}}{r_{c_{R}}{ }^{2}+r_{R}{ }^{2}}\right)\right]
$$

It should be noted that there are some subtle yet significant differences between the velocity profile of the vortex model used in this study and the velocity profile of a Rankine vortex model. The tangential velocity of a Rankine vortex is defined as:

$$
V_{\theta}=\left\{\begin{array}{cl}
\Gamma r / 2 \pi r_{c}^{2} & , r<r_{c} \\
\Gamma / 2 \pi r & , r \geq r_{c}
\end{array}\right.
$$

The difference in the vortex velocity profile of the two models is illustrated in figure 3 for the same core radius and circulation strength. A Rankine vortex has twice the velocity at the core radius as the model proposed by Burnham. At large radii the models converge. The Burnham model was selected for this simulation because it provided a better fit to the measured wind tunnel and flight data that the simulation will be validated against. The effect of different vortex models on the simulation results is not part of this study but is part of future planned research.

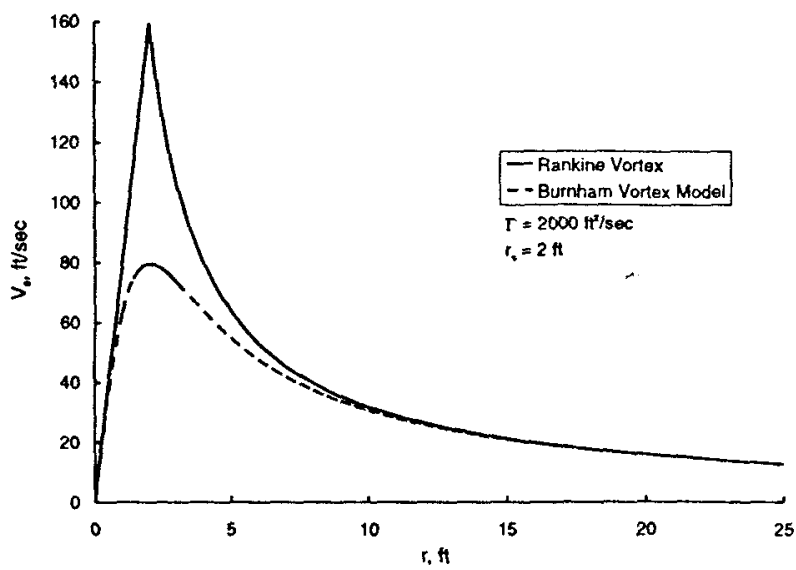

Figure 3. Tangential velocity profiles of two different vortex models. 
For this simulation study the axis system of the wake model was aligned with the runway axis system shown in figure 1. The lateral spacing and core radius of the vortices were set to represent the wake similar to a B727 size airplane. The core radius for both vortices was set at 2 feet $\left(r_{c_{L}}=r_{c_{R}}=2\right)$. The circulation, altitude and lateral displacement of the vortices were varied throughout the study. The vortex pair were constrained to be symmetrical $\left(z_{L}=z_{R}, \Gamma_{L}=\Gamma_{R}\right)$. The lateral displacement of the wake relative to the runway centerline was referenced from the left or port vortex $\left(y_{w}=y_{L}\right)$. The right or starboard vortex was space 84 feet to the right of the left vortex $\left(y_{R}=y_{L}+84\right)$. The effect of the ground plane at the lower altitudes was not accounted for in the wake model.

\section{Vortex Encounter Aerodynamics}

The aerodynamic effect of the wake on the encountering airplane was modeled using a strip theory method similar to that used in references $6,7,8$ and 9 . Strip theory is a simple method in which the wing, the horizontal stabilizer and the vertical stabilizer are divided into a series of chordwise strips, as shown in figure 4. Each strip is treated as a 2-dimensional (2D) airfoil for which the lift at the quarter-chord point is computed as a function of the flow incidence angle at the three-quarter-chord point. The incremental contribution of each strip is summed to determine the forces and moments on the airplane.

Each strip is defined by its area, 2D lift-curve slope, angle of incidence, dihedral angle, and the body axis coordinates of the quarter and three-quarter-chord points at the mid-span of the strip. The $2 \mathrm{D}$ lift-curve slope of each strip on the wing and horizontal stabilizer

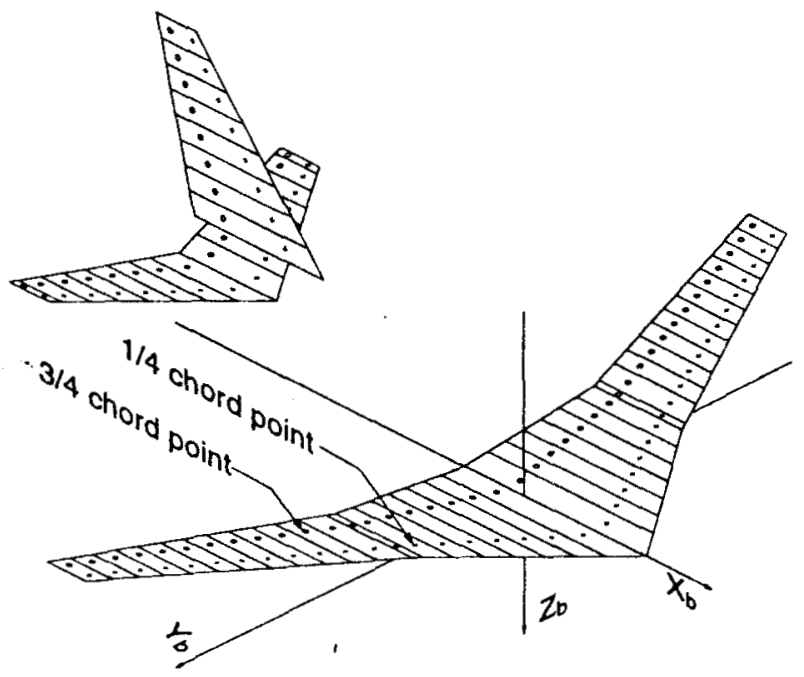

was weighted to yield the proper span load distribution and total lift curve slope of the airplane in a uniform flow field. The lift-curve slopes of the vertical stabilizer strips were weighted to yield the correct value of $C_{Y_{\beta}}$ for the airplane. This resulted in an over estimate of $C_{l_{\beta}}$ and $C_{r_{\beta}}$. The significance of this over estimate will be discussed in the modeling error sensitivity section. A more detailed description of the strip theory force and moment calculation is provided in reference 11 .

The change in the aerodynamic forces and moments due to the wake was determined by taking the difference between the strip theory calculation with the wake velocities included and the same calculation with the wake velocities set to zero. For example:

$$
\Delta C_{L_{w}}=C_{L_{\text {wake }}}-C_{L_{\text {no wake }}}
$$

The change in the force and moment coefficients due to the wake were then added to the baseline sixdegree-of-freedom simulation coefficients. Because the wake effect is computed as the difference between the two strip theory calculations it is more important to correctly model the "slope" terms (e.g., $C_{L_{\alpha}}$ and $C_{Y_{\beta}}$ ) than the total force coefficients (e.g., $C_{L}$ or $C_{Y}$ ).

\section{Landing Criteria}

As was discussed in the introduction, the objective of this study was to investigate the sensitivity of various landing criteria in defining the wake decay required for a B737-100 to safely encounter a wake and land. This analysis requires the establishment of some criteria to define a safe and acceptable landing. Several metrics were selected as candidate safe landing criteria based on the wake hazard research conducted in the 1970's.' 8.9 Maximum bank angle and lateral and vertical deviation from the flight path were selected as performance criteria. The maximum bank angle limit was varied from $7^{\circ}$ to $12^{\circ}$ in $1^{\circ}$ increments.

A proposed auto-land certification requirement for satellite navigation systems (ref. 10) was used to define the lateral and vertical deviation limits. These limits are presented in Table 1 as a function of altitude. The dimensions correspond to approximately a $1^{\circ}$ localizer deviation and a $0.3^{\circ}$ glideslope deviation. The horizontal deviations were computed relative to the localizer centerline. The vertical path deviations were computed relative to a baseline vertical profile. The profile was basically a $3^{\circ}$ glideslope that included the flair maneuver prior to touchdown.

Figure 4. Strip model of B737-100. 


\begin{tabular}{|c|c|c|}
\hline $\begin{array}{c}\text { Altitude } \\
\text { feet }\end{array}$ & $\begin{array}{c}\text { Lateral Limit } \\
\text { feet }\end{array}$ & $\begin{array}{c}\text { Vertical Limit } \\
\text { feet }\end{array}$ \\
\hline 0 & \pm 27 & 0 \\
\hline 50 & \pm 51 & \\
\hline 100 & \pm 75 & \pm 15 \\
\hline 200 & \pm 110 & \pm 32 \\
\hline 250 & \pm 118 & \pm 36 \\
\hline 300 & \pm 125 & \pm 40 \\
\hline 400 & \pm 158 & \pm 51 \\
\hline 500 & \pm 192 & \pm 62 \\
\hline 750 & \pm 275 & \pm 89 \\
\hline 1000 & \pm 358 & \pm 116 \\
\hline 1250 & \pm 442 & \pm 143 \\
\hline 1500 & \pm 525 & \pm 170 \\
\hline
\end{tabular}

Table 1 - Proposed flight path deviation limits for a satellite based auto-land system.

The only non-performance criteria examined in this study was the ratio of the wake induced rolling moment to the maximum roll control power of the airplane.

$$
\delta_{w}=\frac{C_{l_{w}}}{C_{l_{\max } \text { wheel }}}
$$

This criterion was suggested in reference 12 from results of wake encounter flight tests. The maximum roll-control power ratio limit $\left(\delta_{w}\right)$ was varied from 0.5 to 0.7 in 0.1 increments. It should be noted that the maximum roll-control power ratio for the auto-land system is:

$$
\delta_{w_{\text {auto }}}=\frac{C_{I_{w}}}{0.374 C_{I_{\max \text { wheel }}}}=2.674 \delta_{w}
$$

\section{Simulation Analysis}

A series of wake encounter simulations were conducted to derive the maximum wake circulation strength $(\Gamma)$ for a given wake position $\left(y_{w}, z_{w}\right)$ that satisfied each safe landing criterion investigated. For example, figure 5 shows the maximum circulation contours for a $10^{\circ}$ maximum bank angle limit as a function of wake altitude and lateral position. The wake position where the bank limit is reached with the lowest circulation strength occurs when the left vortex is between 10 and 16 feet to the right of the airplane centerline and the wake is no more than 200 feet above the runway. Similar contours were created for each of the criteria investigated. The minimum wake strength at each altitude is obtained from the contours to define the maximum circulation boundary as a function of altitude.

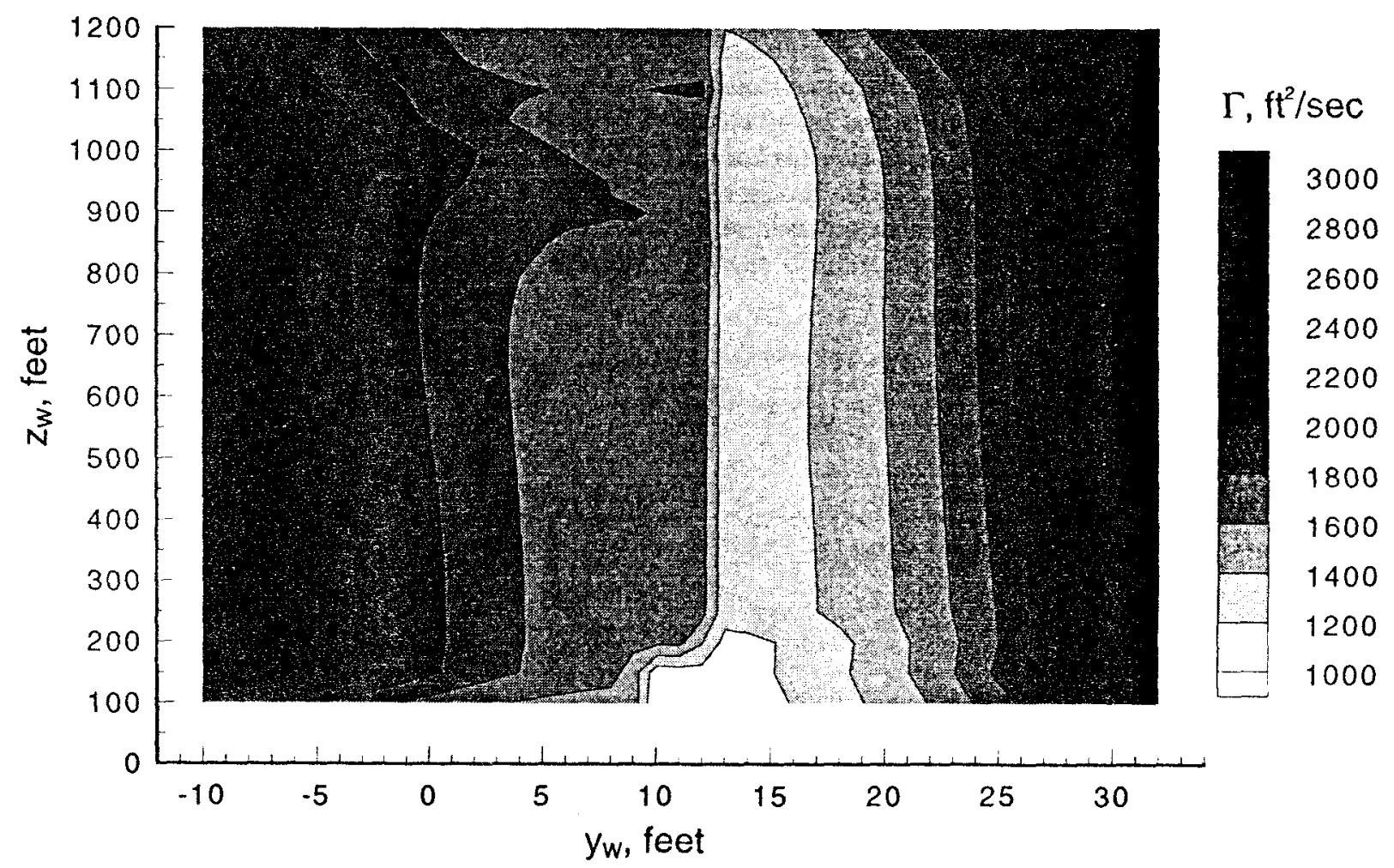

Figure 5. Maximum circulation contours relative to the left vortex position for a $10^{\circ}$ maximum bank angle limit. 


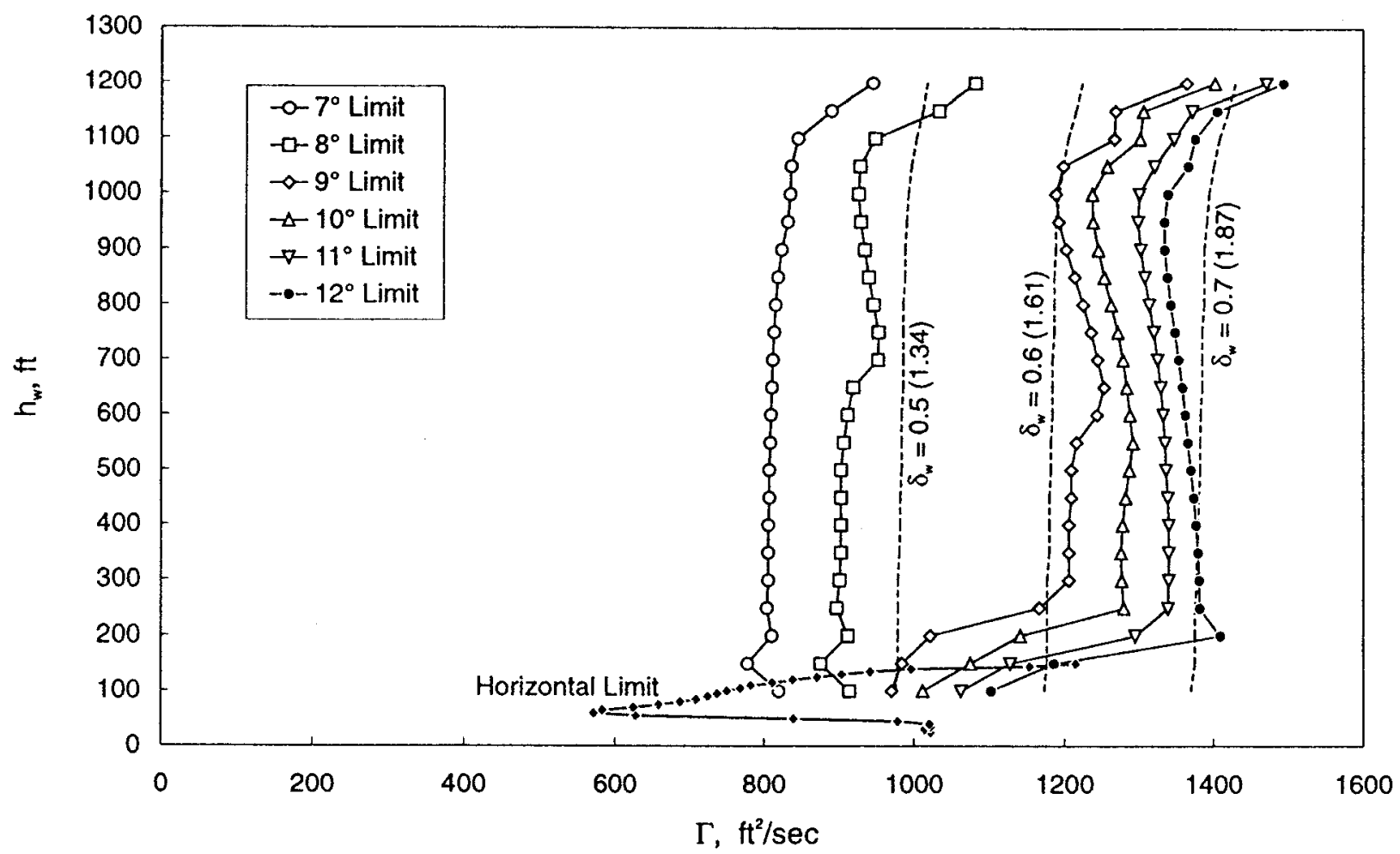

Figure 6. Boundary of wake circulation as a function of wake altitude for various acceptable landing criteria.

Figure 6 shows the wake strength boundaries as a function of wake altitude for the various acceptable landing criteria. The control power boundaries are presented as labeled dashed lines. The value in parentheses is the autopilot control power ratio. The vertical tunnel limit was not a limiting criterion relative to the horizontal limit and is not included in the figure.
At the lower altitudes $\left(h_{w} \leq 150 \mathrm{ft}\right)$ the horizontal tunnel limit is the limiting criteria. For wakes above 150 feet the control power ratio or maximum bank angle is the limiting criteria. The control power boundaries and the maximum bank angle boundaries are very similar. The control power boundaries are nearly constant with altitude, as are the bank angle boundaries between 200

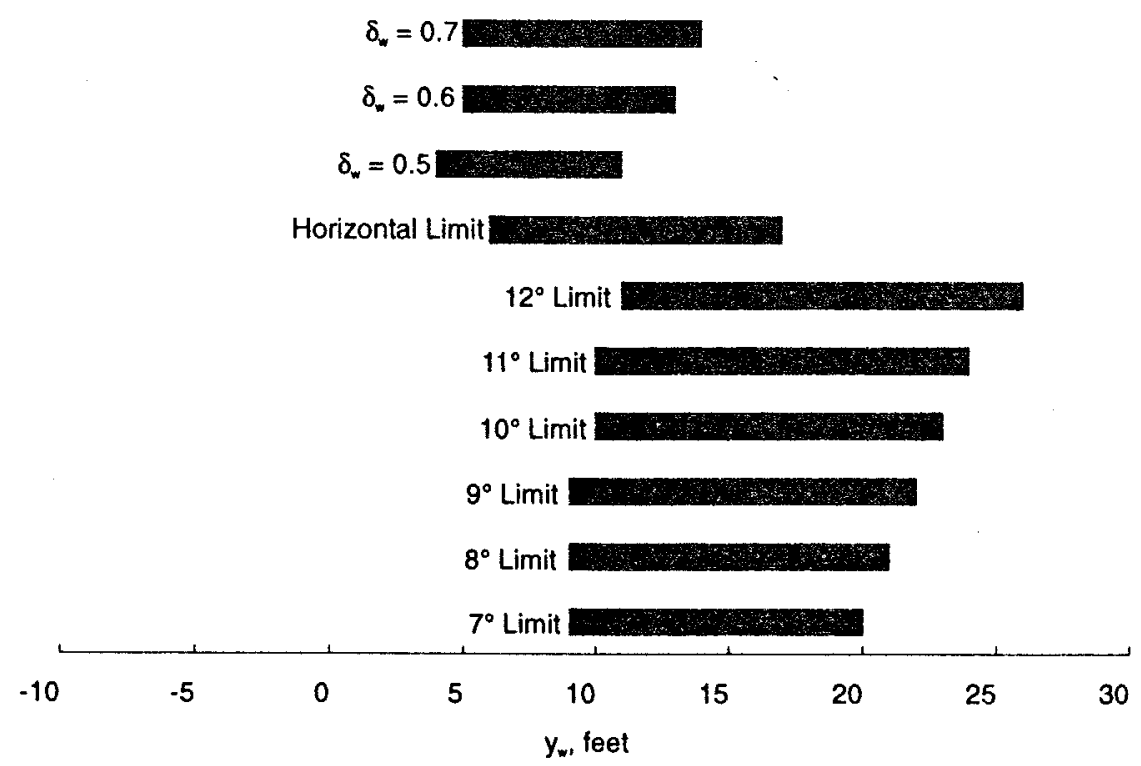

Figure 7. Wake location range of minimum circulation for various acceptable landing criteria. 


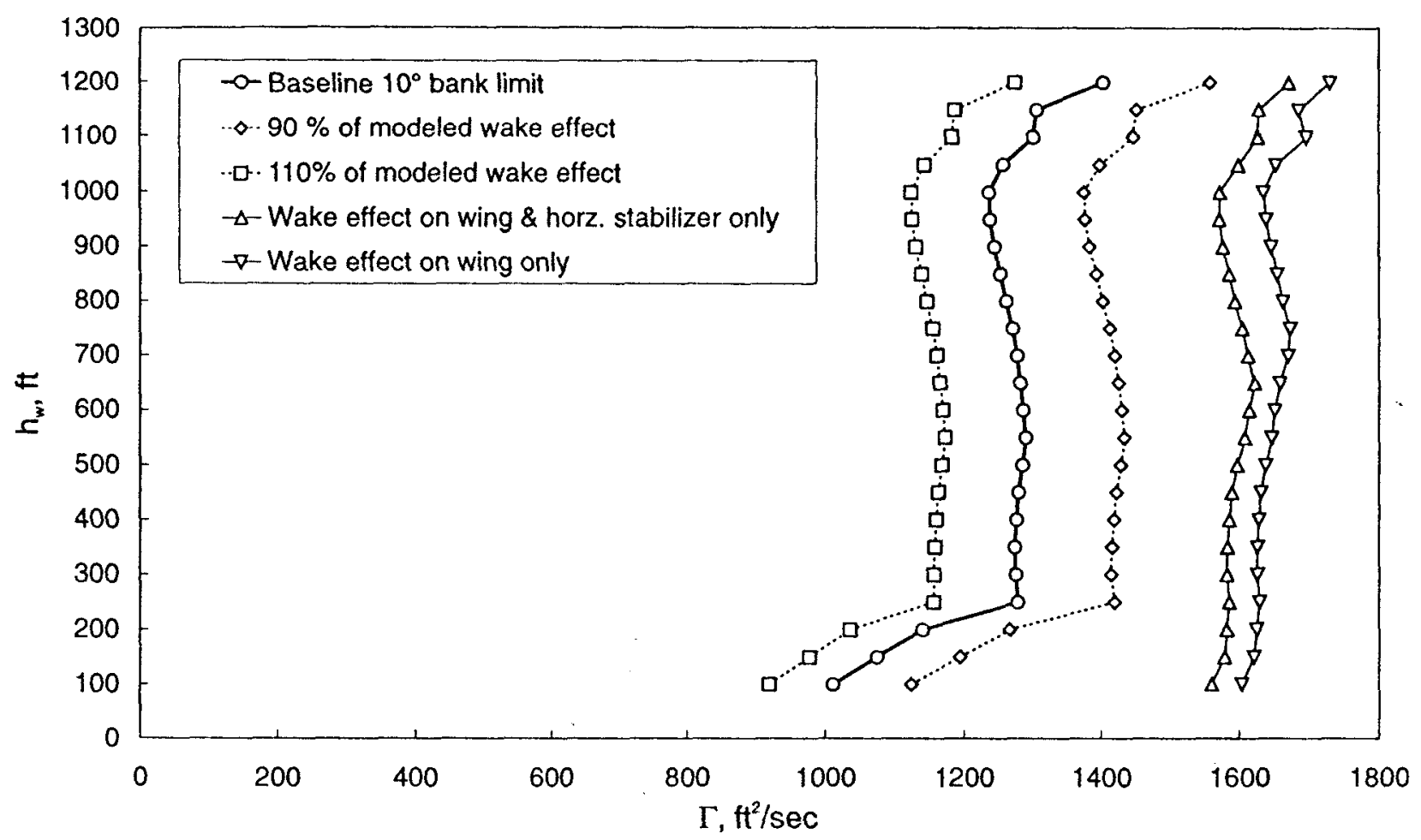

Figure 8. Sensitivity of modeling error and methods on $10^{\circ}$ bank angle boundary.

feet and 1000 feet. The large change in the bank angle boundaries below 200 feet is primarily due to the increase in the tracking gains as the localizer and glideslope signals narrow near the threshold. At altitudes above 1000 feet the variation may be due to reduced tracking gains or due to some of the wake effect being compensated for when the airplane is initially trimmed prior to the start of the run. The large shift between the $8^{\circ}$ and $9^{\circ}$ boundaries occurs when the maximum bank angle of the wake induced upset is less than the maximum bank angle of the recovery maneuver.

Figure 7 shows lateral range of wake positions (position of left vortex) where the strength was a minimum for each criterion. This minimum would be considered the maximum acceptable circulation for that criterion. Although the control power boundaries and the maximum bank angle boundaries are similar functions of altitude, the lateral wake locations at which the boundaries are defined are slightly different. The wake location at which the control power and horizontal tunnel limits are reached with the minimum circulation occurs with the wake closer to the centerline of the airplane than the bank angle limits. The wake location of minimum circulation also moves farther outboard as the bank angle limit is increased. However, the difference in the location of minimum circulation is well within the variation in tracking performance of airplanes flying the localizer and is therefore probably not significant.

\section{Modeling error sensitivity}

A sensitivity study was conducted to assess the effects of modeling methods and accuracy. The analysis was conducted in two parts. The first part assessed the effect of mismodeling the wake encounter aerodynamics. This was done by altering the output of the wake encounter model by \pm 10 percent. The modified simulation was then used to establish new limit boundaries. Figure 8 shows the results of the $\pm 10 \%$ modeling error on the $10^{\circ}$ bank angle boundary. The modeling error resulted in a $10 \%$ shift in the maximum circulation. This makes sense, in that the wake velocities are proportional to the circulation and the change in the aerodynamics is proportional to the wake velocities. A $10 \%$ change in one should result in a $10 \%$ change in the other. The effect of the modeling error on the lateral deviation boundary yielded the same results.

A number of wake encounter studies have been conducted which only accounted for the wake effect on the wing and ignored the tail effect. The second part of the analysis assessed the sensitivity of this modeling method. Figure 8 shows the results of modeling just the wing and horizontal stabilizer, and the wing alone, on 


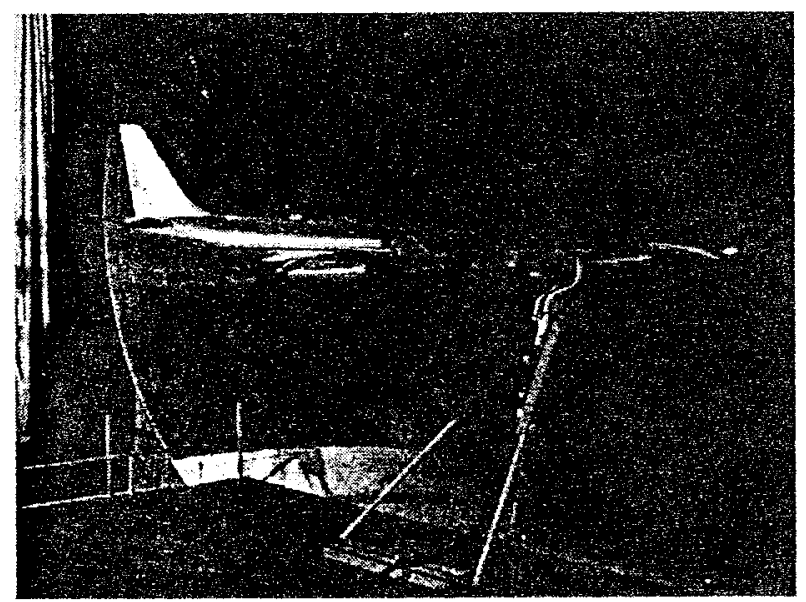

Figure 9. Test of wake effect on a B737-100 airplane in NASA Langley's 30x60 tunnel.

the $10^{\circ}$ bank angle boundary. The results indicate that the vertical stabilizer can have a profound effect on the boundary values. However, the vertical stabilizer effect may be exaggerated due to the current strip theory implementation. The current implementation assumes that the vertical stabilizer is the sole source of $C_{Y_{\beta}}$ for the airplane and neglects the fuselage contribution. This results in the strip theory over predicting the vertical stabilizer contribution and yielding high values for $C_{l_{\beta}}$ and $C_{r_{\beta}}$. A series of flight and wind tunnel tests to measure the wake effect on the airplane aerodynamics have been conducted at NASA's Langley Research Center (figure 9). The results of these tests are currently being analyzed and should help resolve this issue. This may change the magnitude of the circulation values for some of the boundaries, but the general trends are not expected to change.

\section{Concluding Remarks}

This study is part of a planned series of studies to establish criteria for acceptable wake encounters. The control input for the simulation was generated from an auto-land system that had less than half of the full rollcontrol authority of the airplane. This may result in acceptable encounter boundaries that are considered overly conservative to a pilot flying the landing. However, if automatic landings are to be performed under reduced separation conditions then the acceptable encounter criteria must reflect the limits of such a system.

The major results of this simulation study can be summarized as follows: a) The vertical deviation boundary was not a limiting criterion and the horizontal boundary was only limiting for wakes at 150 feet or below.

b) The control power boundaries and the maximum bank angle boundaries are very similar.

c) The lateral position of the wake where the acceptable landing criterion is exceeded with the lowest circulation occurs when the left vortex is offset to the right of the airplane centerline or conversely when the right vortex is offset to the left of the airplane centerline.

d) The wake lateral position of minimum circulation is farther outboard for the maximum bank angle boundaries than for the control power or horizontal deviation limits.

e) Sensitivity study results indicate that the vertical stabilizer can have a profound effect on the boundary values and must be accurately modeled to establish valid boundaries.

Research is ongoing to validate the simulation encounter models with flight test and wind tunnel data. This may change the magnitude of the circulation values for some of the boundaries, but the general trends are not expected to change.

\section{$\underline{\text { References }}$}

1. Scott, William B.: "Technology, Economics Fuel Public-Private Cooperation". Aviation Week \& Space Technology, June 7, 1993, pp. 69-76.

2. Hallock, J. N.: Aircraft Wake Vortices: An Assessment of the Current Situation. DOT-FAA-RD90-29, January 1991.

3. Machol, R. E.: Wake Vortices - A Primer. FAA Aviation Safety Journal, Pages 16 - 19, Vol. 3, No. 1, 1993.

4. Airman's Information Manual - Official Guide to Basic Flight Information and ATC Procedures. U.S. Department of Transportation, Federal Aviation Administration, Para 7-49, February 4, 1993

5. Wolverton, David A.; Dickson, Richard W.; Clinedinst, Winston $C_{\text {.; }}$, and Slominski, Christopher. J.: Advanced Transport Operating System (ATOPS) Flight Management / Flight Controls (FM/FC) Software Description, NASA CR-191457, April 1993.

6. Nelson, R. C.; and McCormick, B. W.: "The Dynamic Behavior of an Aircraft Encountering Aircraft Wake Turbulence," AIAA Paper No. 74-447, Anaheim, CA, Aug. 1974. 
7. Johnson, W. A., Teper, G. L., and Rediess, H. A., "Study of Control System Effectiveness in Alleviating Vortex Wake Upsets," Journal of Aircraft, Vol. 11, No. 3, March 1974, pp. 148-154.

8. Sammonds, R. I., Stinnett, G. W., Jr., and Larson, W. E., "Hazard Criteria for Wake Vortex Encounters," NASA TM-X-62473, Aug. 1975.

9. Hastings, E. C., and Keyser, G. L., Jr., "Simulator Study of Vortex Encounters by a Twin-Engine, Commercial, Jet Transport Airplane," NASA TP 1966, Feb. 1982.

10. Kelly, R. J.; and Davis, J. M.: "Required Navigation Performance (RNP) for Precision Approach and Landing with GNSS Application," Navigation: Journal of The Institute of Navigation, Vol. 41, No. 1, Spring 1994.

11. Reimer, Heidi M.; and Vicroy, Dan D.: "A Preliminary Study of a Wake Encounter Hazard Boundary for a B737-100 Airplane," NASA TM 110223, April 1996.

12. Andrews, William H.; Robinson, Glenn H.; and Larson, Richard R.: "Exploratory Flight Investigation of Aircraft Response to the Wing Vortex Wake Generated by Jet Transport Aircraft," NASA TN D-6655, March 1972. 